This item was submitted to Loughborough's Research Repository by the author.

Items in Figshare are protected by copyright, with all rights reserved, unless otherwise indicated.

\title{
Competing for a duopoly: international trade and tax competition
}

PLEASE CITE THE PUBLISHED VERSION

http://dx.doi.org/10.1111/j.1540-5982.2010.01594.x

\section{PUBLISHER}

John Wiley and Sons (@ Canadian Economics Association)

\section{VERSION}

AM (Accepted Manuscript)

\section{PUBLISHER STATEMENT}

This work is made available according to the conditions of the Creative Commons Attribution-NonCommercialNoDerivatives 4.0 International (CC BY-NC-ND 4.0) licence. Full details of this licence are available at: https://creativecommons.org/licenses/by-nc-nd/4.0/

\section{LICENCE}

CC BY-NC-ND 4.0

\section{REPOSITORY RECORD}

Ferrett, Benjamin E., and lan Wooton. 2019. "Competing for a Duopoly: International Trade and Tax Competition”. figshare. https://hdl.handle.net/2134/23373. 
Revised version: February 2009

\title{
Competing for a Duopoly:
}

\section{International Trade and Tax Competition}

\begin{abstract}
We analyse the tax/subsidy competition between two potential host governments to attract the plants of firms in a duopolistic industry. Competition between identical countries for a monopoly firm's plant is known to result in subsidy inflation which leaves the winning country indifferent towards hosting the firm. In sharp contrast, we show that, with two firms, both can be taxed in equilibrium with the host countries appropriating the entire social surplus generated within the industry-despite explicit non-cooperation between governments. We extend our baseline model to allow for differences in country size to determine when the size asymmetry becomes sufficiently large to change the nature of the equilibrium, inducing concentration of production in the larger country.
\end{abstract}

Keywords: tax competition; foreign direct investment; oligopoly; market size asymmetries.

JEL classifications: F12; F23; H25; H73.

Corresponding author: Ian Wooton, Department of Economics, University of Strathclyde, Sir William Duncan Building, 130 Rottenrow, Glasgow G4 0GE, United Kingdom. Telephone: +44 141548 3580. Fax: +44 141548 4445. Email: ian.wooton@strath.ac.uk.

Acknowledgements: The authors are grateful for comments from participants in seminars at WZB Berlin, Exeter and Nottingham Universities, the MidWest Trade conference in Nashville and ETSG, Dublin. Particular thanks are due to Michael Devereux, Rachel Griffith, Andreas Haufler and two anonymous referees for their suggestions.

Ben Ferrett

Loughborough University and GEP, University of Nottingham

Ian Wooton

University of Strathclyde, CESifo and CEPR 


\section{Introduction}

The idea that competition for foreign direct investment (FDI) results in a "race to the bottom" in taxes is a recurrent theme of public opinion in developed countries. Bidding contests between national governments for the footloose plants of multinational enterprises (MNEs) tend, according to this view, to depress corporate tax revenues and inflate subsidy payments. ${ }^{1} \quad$ The end result is that MNEs are perceived as capturing a disproportionate share of the benefits of FDI. During the late 1990s, these public concerns were reflected at the policy level in the launching of initiatives by both the European Union and the OECD to combat "harmful" tax competition (see European Commission, 1997; OECD, 1998).

Some possible causes of downward pressure on equilibrium corporate tax rates (or an upward pressure on subsidy payments) are suggested by existing formal analyses of tax/subsidy competition for FDI. These have focused on the polar cases of industry structure-perfect competition and monopoly. Zodrow and Mieszkowski (1986), for example, examine the determination of capital taxes and public good provision in a world of perfect competition and small, open economies. In that situation, a rise in one country's capital tax creates a positive externality as capital is driven abroad, benefiting other countries as the capital inflows result in higher tax revenues and wages. In a non-cooperative environment, national governments fail to account for these external benefits and, consequently, set tax rates and public good provision at inefficiently low levels. In contrast, Haufler and Wooton (1999) focus on a tax/subsidy competition game between two potential host countries for a single firm's production plant. With identical potential host countries, a race to the bottom occurs

\footnotetext{
1 For example, according to the eminent British political philosopher, John Gray, "(t)ax competition among advanced states works to drain public finances and make a welfare state unaffordable" (Gray, 1998, p. 88). Some argue that the race to the bottom will manifest itself more broadly-such as in a scramble to dismantle environmental protections (for an analysis of which, see Markusen et al., 1996). However, our focus is tax/subsidy competition.
} 
in taxes such that the winning location pays a subsidy to the firm in equilibrium and gains no benefit from hosting the FDI. ${ }^{2}$

However, in contrast to these theoretical perspectives, much empirical evidence suggests neither perfect competition nor monopoly is the appropriate setting to analyze tax competition for FDI. In the data, FDI intensity is generally found to be positively correlated with measures of source- and host-country product-market concentration. Davies and Lyons (1996, chapter 7), for example, report a correlation coefficient of +0.5 between indices of the "transnationalization" within the EU of large European manufacturers and production concentration across firms at the EU level. ${ }^{3}$ This suggests using an imperfectly competitive environment to analyze the competition by national governments for FDI. Consequently, we use formal, game-theoretic analysis to develop intuition on how tax/subsidy competition works in international oligopolies and to determine how the social surplus is divided between host countries and MNEs.

In our model, two potential host countries compete to attract the FDI of two firms, which are entirely owned outside the host countries. By locating a plant in either country, a firm can serve both host countries' product markets. The two host-country governments set their taxes/subsidies independently to maximize national social welfare. We assume that, ceteris paribus, nations prefer local production to imports and this creates the incentive for national governments to compete to attract the FDI. This motivation arises in our model through the existence of trade costs which make servicing a national market cheaper with local production than through imports. This cost difference is passed on to consumers as

\footnotetext{
${ }^{2}$ In the Haufler and Wooton model, the competition between identical countries for the monopolist is a standard first-price auction. Other analyses of bidding for a monopolist that produce positive subsidies in equilibrium are Black and Hoyt (1989), King et al. (1993), Haaparanta (1996), and Menezes (2003).

${ }^{3}$ For additional evidence, see Caves (1996, section 4.1) and UNCTAD (1997, chapter 4).
} 
price savings, so consumers prefer local production to imports. ${ }^{4}$

Our central result is presented in the context of a baseline, symmetric model with identical countries. We show that, subject to the fulfilment of an intuitive condition on the fixed cost of plants, a perfect equilibrium exists where one firm locates in each country and the countries fully capture the firms' profits in taxes. Our duopoly result differs strikingly from that where two identical countries compete in taxes/subsidies for a single firm. In the latter situation, the equilibrium subsidy equals the countries' (common) valuation of local production over imports and we have the familiar "race to the bottom" outcome where the winning country is left indifferent towards hosting the plant.

In our symmetric equilibrium, it is clear that the firms will locate in different countries as the existence of trade costs means that co-location would drive down the firms' variable profits and result in post-tax losses. We then investigate the conditions under which the qualitative features of the equilibrium of our baseline model survive the introduction of differences in the sizes of the countries. We derive a condition on the market-size asymmetry between the two host countries under which production remains internationally dispersed and the countries continue to set corporate taxes to extract fully the firms' profits. If the market-size aymmetry becomes too great, this equilibrium breaks down. When the size difference between the host countries is sufficiently great, the larger country is able to attract both firms in equilibrium and impose a corporate tax, despite the offer of a subsidy by the smaller country. This new equilibrium has similar features to that derived by Haufler and Wooton (1999) for monopoly and a large asymmetry in country size. ${ }^{5}$

\footnotetext{
4 This is not the only potential benefit that might arise from local production. For example, an MNE may offer a wage premium over workers' outside options, an extreme case of which occurs when inward FDI relieves involuntary unemployment (Haaparanta, 1996; Bjorvatn and Eckel, 2006). Alternatively, the inward FDI may be associated with localized technological spillovers to indigenous firms (Fumagalli, 2003; Olsen and Osmundsen, 2003).

${ }^{5}$ Ottaviano and van Ypersele (2005) also present a qualitatively identical equilibrium in a model of tax competition between countries of different sizes under large-group monopolistic competition.
} 
To the best of our knowledge, Janeba (1998) is the only existing formal analysis of tax/subsidy competition under oligopoly. However, both Janeba's modelling set-up and the resulting incentives are very different from ours. Like us, he considers two host countries for FDI and two mobile firms. In his model, each country owns one of the firms, and the government policy instrument is an output tax/subsidy, which can be interpreted as a profit tax/subsidy. The firms compete à la Cournot on a third market through costless exports. When firms are constrained to produce in their home countries, as in Brander and Spencer (1985), both governments use output subsidies in equilibrium to make their national firms more aggressive on the product market (profit-shifting). However, when the firms' plants are mobile, tax competition drives the countries' output subsidies down to zero. Key to this result is the assumption of nondiscrimination between domestic and foreign firms. Therefore, starting from the Brander and Spencer equilibrium, each government has an incentive to cut its output subsidy under plant mobility, thereby driving its own firm abroad where it will be subsidized by foreign taxpayers. In contrast to our model, the incentives created by Janeba's set-up mean that (in the presence of output subsidies) governments do not wish to attract inward FDI, a characteristic which seems difficult to reconcile with experience. Another important difference is that Janeba's "third market" assumption means that the impact of national market-size asymmetries cannot be assessed.

We set out our model of tax competition to attract a duopoly industry in section 2 . The baseline, symmetric version of the model is solved in section 3 . In section 4 , we address the question of whether this symmetry depends on the assumption of identical host countries by allowing one of the host countries to have a larger national market. We conclude in section 5 by discussing some potential extensions to our analysis and by considering the restrictiveness of some of the specific assumptions we have imposed. 


\section{Model}

We model the tax/subsidy competition between two host countries, $A$ and $B$, for the plants of two identical firms. The two firms produce a homogeneous good and county $A$ is $n \geq 1$ times larger than $B$. The national demand curves are:

$$
Q_{A}=n\left(\alpha-p_{A}\right) \text { and } Q_{B}=\alpha-p_{B}
$$

where $p_{i}$ is the market price in country $i$. Parameter $\alpha$ measures the common reservation price, and $n$ is an index of the size advantage of country $A .{ }^{6}$

Our game has three stages and complete but imperfect information.

Stage 1: Governments $A$ and $B$ simultaneously and irreversibly announce their tax offers, $T_{A}$ and $T_{B}$.

Stage 2: The two firms simultaneously and irreversibly pick locations, choosing between $\{\varnothing, A, B\}$, where $\varnothing$ is the no-entry option.

Stage 3: Firms compete à la Cournot to serve both countries' markets.

We solve the game backwards to isolate its subgame perfect Nash equilibria in pure strategies.

From the viewpoint of the firms, the governments' taxes are location-specific fixed costs (corporate taxes are levied on a source basis). For $i \in\{A, B\}, T_{i}>0$ is a lump-sum tax, $T_{i}<0$ represents a lump-sum subsidy, and $T_{i}=0$ is laissez-faire. We assume that the governments cannot discriminate between firms when setting taxes. ${ }^{7}$

\footnotetext{
${ }^{6}$ These demand functions are consistent with quasi-linear preferences.

${ }^{7}$ Firms are identical in every respect (costs, technology, ownership structure, etc.) and are assumed to arrive simultaneously and so there is no natural basis for discrimination.
} 


\subsection{Profits of the Firm}

In addition to taxes/subsidies, firms face three types of cost, all of which are independent of the location of production. The marginal production cost is $w$ and a specific trade cost of $\tau>0$ applies to goods shipped between the two host countries. We further assume that if a firm chooses $\varnothing$, it cannot serve markets $A$ and $B$ from a third country due to prohibitive trade barriers.

If only one of the firms establishes a plant, then the market equilibrium is the monopoly solution. Variable profits per head are:

$$
\begin{gathered}
\pi_{L \varnothing} \equiv \frac{1}{4}(\alpha-w)^{2}, \quad \text { on local sales at marginal cost } w ; \\
\pi_{F \varnothing} \equiv \frac{1}{4}(\alpha-w-\tau)^{2}, \quad \text { on export sales at marginal cost } w+\tau .
\end{gathered}
$$

Trade costs ensure that $\pi_{L \varnothing}>\pi_{F \varnothing}$. That is, local production is more profitable than serving a market though exports.

If both firms establish plants, then the market equilibrium is given by Cournot duopoly. Variable profits per head depend on both firms' locations:

$$
\left.\begin{array}{cl}
\pi_{L F} \equiv \frac{1}{9}(\alpha-w+\tau)^{2}, & \text { if firm produces locally and its rival produces abroad; } \\
\pi_{L L} \equiv \frac{1}{9}(\alpha-w)^{2}, & \text { if both firms produce locally; } \\
\pi_{F F} \equiv \frac{1}{9}(\alpha-w-\tau)^{2}, & \text { if both firms produce abroad; } \\
\pi_{F L} \equiv \frac{1}{9}(\alpha-w-2 \tau)^{2}, & \text { if firm produces abroad and its rival produces locally. }
\end{array}\right\}
$$

If the firms establish plants in different countries, we assume that trade cross-hauling occurs.

That is, the homogeneous good is simultaneously exported and imported. This requires that $\tau \leq \bar{\tau}$ where the prohibitive trade cost is:

$$
\bar{\tau} \equiv \frac{1}{2}(\alpha-w)
$$

Condition (3) ensures that every possible Cournot equilibrium is interior. Given this trade 
cost, we know from (2) that:

$$
\left.\begin{array}{c}
\pi_{L F}>\pi_{L L}>\pi_{F F}>\pi_{F L}, \\
\pi_{L F}+\pi_{F L}>\pi_{L L}+\pi_{F F} .
\end{array}\right\}
$$

A firm's total operating profits, $\Pi_{i j}$, are defined as the sum of profits from serving both markets when the firm is located in country $i$ and its competitor is in country $j$. We assume that the fixed cost of a plant, $C$, is sufficiently large to ensure that firms establish at most one plant. For a monopolist, $j=\varnothing$ and total profits for the firm are:

$$
\begin{aligned}
\Pi_{A \varnothing} & \equiv n \pi_{L \varnothing}+\pi_{F \varnothing}-C, \\
\Pi_{B \varnothing} & \equiv \pi_{L \varnothing}+n \pi_{F \varnothing}-C,
\end{aligned}
$$

With trade costs, the larger market is the more profitable plant location. That is, $\Pi_{A \varnothing}>\Pi_{B \varnothing}$ for any $n>1$ and $\tau>0$. If $\tau=0$, then profits are independent of the location of production.

Under duopoly, the total operating profits of a firm are:

$$
\left.\begin{array}{ll}
\Pi_{A A} \equiv n \pi_{L L}+\pi_{F F}-C, & \Pi_{A B} \equiv n \pi_{L F}+\pi_{F L}-C, \\
\Pi_{B A} \equiv \pi_{L F}+n \pi_{F L}-C, & \Pi_{B B} \equiv \pi_{L L}+n \pi_{F F}-C .
\end{array}\right\}
$$

From (4) we can determine that:

$$
\left.\begin{array}{rr}
\Pi_{A B}=\Pi_{B A}>\Pi_{A A}=\Pi_{B B}, & \text { for } n=1 ; \\
\Pi_{A B}>\Pi_{B A}, \quad \Pi_{A A}>\Pi_{B B}, & \text { for } n>1 ; \\
\Pi_{A B}>\Pi_{A A}, & \text { for } n \geq 1 .
\end{array}\right\}
$$

There are three elements to (6). Firstly, with equally sized countries, profits are higher when production is geographically dispersed. Second, when $A$ has a larger market than $B$, regardless of whether production is to be geographically dispersed or concentrated in one country, locating in $A$ is more profitable than setting up in $B$. Third, a firm located in $A$ benefits if its rival moves production abroad to $B$ whatever the relative sizes of the two 
countries. However, the same cannot be said of a firm based in $B$ as the ranking of $\Pi_{B A}$ and $\Pi_{B B}$ is crucially sensitive to $n$, a property that will be important for the analysis of section 4 .

Firms choose their locations independently to maximize post-tax profits. Let

$$
\Delta_{j} \equiv \Pi_{A j}-\Pi_{B j}
$$

be the operating profit differential (i.e. excluding tax/subsidy differences) arising from locating a plant in $A$ rather than $B$, when the rival firm locates in country $j$. We call this country $A$ 's "geographic advantage". From (4) and (5), we know that $\Delta_{B}>\Delta_{A} . \Delta_{j}$ is increasing in $n$ because locating in $A$ becomes more attractive as its market grows. However, as $\Delta_{j}$ may be negative, so being in $A$ may not always be the more advantageous location.

We can determine a firm's best response to the location choice of the other firm. Given its rival's choice of $j \in\{A, B, \varnothing\}$, a firm has the following locational preferences:

$$
\left.\begin{array}{l}
A \succ \varnothing \quad \text { if and only if } T_{A}<\Pi_{A j} ; \\
B \succ \varnothing \quad \text { if and only if } T_{B}<\Pi_{B j} ; \text { and } \\
A \succ B \text { if and only if } T_{A}<\Delta_{j}+T_{B} .
\end{array}\right\}
$$

\subsection{Welfare and Governments}

As imports are subject to trade costs, local production benefits a country's citizens by offering lower prices. Consumers would be indifferent to the location of production if trade were free.

When there is a single firm in the market, the consumer surplus per head is:

$$
\begin{aligned}
S_{L \varnothing} \equiv \frac{1}{8}(\alpha-w)^{2}, & \text { if the monopolist produces locally; while } \\
S_{F \varnothing} \equiv \frac{1}{8}(\alpha-w-\tau)^{2}, & \text { if the monopolist produces abroad. }
\end{aligned}
$$

Clearly, with trade costs, local production is better as $S_{L \varnothing}>S_{F \varnothing}$, creating an incentive to attempt to attract the FDI. 
With two firms, the locational configurations of production become more complex. Consumer surplus per head under Cournot duopoly is:

$$
\begin{array}{cl}
S_{L L} \equiv \frac{2}{9}(\alpha-w)^{2}, & \text { if both firms produce locally; } \\
S_{L F} \equiv S_{F L} \equiv \frac{1}{18}(2 \alpha-2 w-\tau)^{2}, & \text { if one firm is local, other produces abroad; } \\
S_{F F} \equiv \frac{2}{9}(\alpha-w-\tau)^{2}, & \text { if both firms produce abroad. }
\end{array}
$$

These can be ranked as

$$
S_{L L}>S_{L F} \equiv S_{F L}>S_{F F} .
$$

That is, the more firms that produce locally, the better.

We assume that goverments $A$ and $B$ are benevolent, both being motivated by national social welfare, and that they set their taxes/subsidies, $T_{A}$ and $T_{B}$, independently. National social welfare is defined as total consumer surplus plus tax revenues (or minus total subsidy payments). Each government must balance its budget, only being able to redistribute income in a lump-sum manner between its citizens and the foreign MNEs.

The MNEs are assumed to be wholly owned outside of countries $A$ and $B$, so their posttax profits do not contribute to social welfare in the host countries. ${ }^{8}$ Moreover, we assume throughout the bulk of our analysis that the firms' pre-tax profits are positive in all location configurations. $^{9}$

\section{Baseline Case: Identical Host Countries}

We now analyze the equilibrium taxes and firm locations in the case where countries $A$ and $B$ are of equal size, $n=1$. This symmetrical case is used to demonstrate our central result.

\section{[FIGURE 1 HERE]}

\footnotetext{
${ }^{8}$ Ferrett and Wooton (2006) examine how changing the international distribution of a monopoly firm's ownership affects the outcome of the tax/subsidy competition for its FDI.

9 The exceptions to this are the existence results in part (i) of each of Proposition 1 and Proposition 3, which place no restrictions on pretax profits.
} 
Figure 1 uses (8) to plot the firms' equilibrium locations as functions of the countries' tax offers, $T_{A}$ and $T_{B}$. Inter-regional boundaries are drawn in the tax space, and the firms' equilibrium response to an offer of $\left(T_{B}, T_{A}\right)$ is indicated by $[i, j]$ where $i, j \in\{A, B, \varnothing\}$. As the countries are the same size, these inter-regional boundaries are symmetric around the $T_{A}=T_{B}$ line. Qualitatively, the relative positions of these boundaries are robust to changes in the transport and plant costs. Reducing $\tau$ cuts $\Delta_{B}=-\Delta_{A}$, the profit advantage to locating abroad from the rival firm, because the firms' profits vary less with their plant locations. With free trade, $\tau=0$, the $[A, B]$ region collapses into the line $T_{A}=T_{B}$. Changing the plant cost $C$ alters all of the $\Pi_{i j}$ terms and shifts the inter-regional boundaries without affecting their relative positions. Figure 1 is drawn for the case where pre-tax profits are positive in every location configuration, even co-location.

Point $E$ in Figure 1 is just below and to the left of $\left(\Pi_{B A}, \Pi_{A B}\right)$ such that the taxes being levied on the firms are an amount $\varepsilon$ less than these values. At $E$, the firms locate in different countries and (almost) all of their profits are captured in tax by the host countries. We shall call $E$ the point of "Full Profit Extraction" (FPE) and it is our candidate for the subgame perfect equilibrium. Suppose that firm 1 locates in $A$. Given that $T_{A}=T_{B}=\Pi_{A B}-\varepsilon$ at $E$, it is clear that firm 2's optimal location is $B$. As $\varepsilon>0$, the firm is (just) profitable in $B$, so it will enter. Were it to choose $A$, competition with its co-located rival would drive down its earnings, making production unprofitable after taxes.

We now derive conditions for the FPE point $E$ to be a bidding equilibrium. As the countries are assumed to be the same size, the model is symmetric. Therefore we focus on country $A$ 's choice of $T_{A}$ given that $T_{B}=\Pi_{B A}$. By varying $T_{A}$, there are three distinct location equilibria that $A$ can induce: $[A, A],[A, B]$, and $[B, \varnothing]$. For any given location equilibrium where it attracts at least one firm, $A$ 's optimal $T_{A}$ will be as big as possible. 
Consumer surplus is determined solely by the location of the firms and is unaffected by $T_{A}$ and therefore the government will want to set the highest tax, conditional on $T_{A}$ inducing the desired location outcome. Therefore, $A$ will never deviate from $E$ to another point in $[A, B]$, and if it deviates to $[A, A]$, it will optimally set $T_{A}=\Pi_{A A}-\varepsilon$.

In order to rule out tax-cutting from point $E$, we need $A$ 's social welfare at $E$ to be at least as great as that just inside $[A, A]$, which means that:

$$
S_{L F}+\Pi_{A B} \geq S_{L L}+2 \Pi_{A A} .
$$

Expanding the profit terms, and rearranging, this yields a lower limit on a firm's fixed costs such that $C \geq \underline{C}$, where

$$
\underline{C} \equiv S_{L L}-S_{L F}+2\left(\pi_{L L}+\pi_{F F}\right)-\left(\pi_{L F}+\pi_{F L}\right) .
$$

The easiest way to think of country $A$ 's taxation incentives when $T_{A}$ is set to fully extract profits is that $A$ reimburses the fixed plant $\operatorname{costs} C$ of the firms it attracts and then completely taxes away their variable profits. Therefore, $C$ acts like the "price" of a firm. (10) requires that $C$ exceed the marginal benefit to $A$ of a second firm, which is the gain in consumer surplus plus the rise in taxable variable profts resulting from having both firms.

We must also rule out tax-raising by government $A$. This requires that $A$ 's social welfare at $E$ be at least as great as that in $[B, \varnothing]$ :

$$
S_{L F}+\Pi_{A B} \geq S_{F \varnothing}
$$

This corresponds to determining an upper limit on fixed costs such that $C \leq \bar{C}$, where

$$
\bar{C} \equiv S_{L F}-S_{F \varnothing}+\left(\pi_{L F}+\pi_{F L}\right) .
$$

By raising its tax from point $E$, country $A$ induces a location equilibrium of $[B, \varnothing]$. That is, it drives the local firm out of the industry altogether. To preclude this, we require that the 
firm "price" $C$ lie below the marginal benefit of the first firm, given in (12). Straightforward algebra shows that $\bar{C}>\underline{C}$ for all nonprohibitive trade costs, $\tau \leq \bar{\tau}$.

Proposition 1 gives our baseline existence result:

\section{Proposition 1 (existence of dispersed equilibrium with FPE)}

Assume that the countries are of equal size $(n=1)$.

(i) A subgame perfect Nash equilibrium characterized by internationally dispersed production and corporate taxes that fully extract profits (i.e. at point $E$ in Figure 1) exists if and only if the plant fixed cost $C$ lies within $[\underline{C}, \bar{C}]$, where $\underline{C}$ and $\bar{C}$ are defined in (10) and (12), respectively.

(ii) The interval $[\underline{C}, \bar{C}]$ is non-empty on all nonprohibitive $\tau$.

(iii) If we additionally assume that pre-tax profits are positive in all location configurations, then a dispersed equilibrium with FPE exists if and only if $C \in\left[\underline{C}, \pi_{L L}+\pi_{F F}\right]$. This interval is smaller than that in $(i)$ and non-empty on $\tau \in\left[\frac{4}{9}(\alpha-w), \bar{\tau}\right]$.

Parts (i) and (ii) of Proposition 1 show that for any $\tau \in[0, \bar{\tau}]$ it is possible to set $C$ so that point $E$ in Figure 1 is an equilibrium. The fact that the equilibrium at $E$ involves FPE is quite striking when contrasted with tax/subsidy competition to attract a monopoly (Haufler and Wooton, 1999). With identical host countries, the monopolist locates in the country offering the lower tax or higher subsidy. In equilibrium, the countries' subsidy offers are driven up to their common valuation of local production over imports, $S_{L \varnothing}-S_{F \varnothing}$. This monopoly case is probably the simplest possible example of the "race to the bottom" where tax/subsidy competition results in a subsidy that leaves the winning country indifferent about hosting the monopolist's plant. The duopoly outcome that we investigate is starkly different. 
In equilibrium at point $E$, the firms are indifferent between entering the industry and staying out, and corporate taxes "race to the top" to capture all the firms' profits.

Part (iii) of Proposition 1 invokes the additional assumption that $\Pi_{A A}=\Pi_{B B} \geq 0$. This is sufficient (but unnecessary) to make pre-tax profits at $E$ positive, so the equilibrium $T_{A}$ and $T_{B}$ represent corporate taxes. Therefore, this assumption allows us to focus on arguably the most empirically relevant case in which effective corporate taxes are positive (Devereux et al., 2002). As $\Pi_{A A} \geq 0$ is a tighter restriction than $C \leq \bar{C}$ in (12), we need to recheck for the existence of equilibrium. Remember that if $\tau<\frac{4}{9}(\alpha-w)$, then we can still select $C$ so that the FPE equilibrium exists; but pre-tax profits under co-location would be strictly negative. ${ }^{10}$

Changing the trade cost $\tau$ will alter the countries' incentives to raise or cut taxes, and therefore also alter the range of plant costs that support the FPE equilibrium, $[\underline{C}, \bar{C}]$. For example, in (10) it is intuitive that the consumer surplus benefit of cutting taxes, $S_{L L}-S_{L F}$, is increasing in $\tau$. However, the level of variable profits that can be extracted through tax, $2\left(\pi_{L L}+\pi_{F F}\right)-\left(\pi_{L F}+\pi_{F L}\right)$, decreases with $\tau$, and this reduction outweighs the consumer surplus gain. Therefore, $\underline{C}$ falls as $\tau$ rises. Straightforward algebra can also be used to show that $\bar{C}$ is U-shaped in $\tau$. Therefore, the interval $[\underline{C}, \bar{C}]$ grows in size as $\tau$ approaches $\bar{\tau}$.

We now consider the uniqueness of equilibrium. The assumption that pre-tax profits are positive implies that point $E$ lies in the NE quadrant of Figure $1 .^{11}$

\section{Proposition 2 (uniqueness of dispersed equilibrium with FPE)}

If pre-tax profits are positive in all location configurations, then the FPE equilibrium described in Proposition 1 is unique.

\footnotetext{
${ }^{10}$ The necessary condition for positive equilibrium taxes is $\Pi_{A B} \geq 0$. This is looser than $\Pi_{A A} \geq 0$, and the existence interval $C \in\left[\underline{C}, \pi_{L F}+\pi_{F L}\right]$ is nonempty on $\tau \in\left[\frac{4}{17}(\alpha-w), \bar{\tau}\right]$.

${ }^{11}$ For clarity, we shall use "geographical" directions, where North (N) is oriented in the direction of $T_{A}$.
} 
Proof: With pre-tax profits always positive, both firms will enter the industry in equilibrium.

Suppose, to the contrary, that in equilibrium at least one of the firms stays outside the industry. Thus, at least one country attracts no firms. Let this empty country be $A$. It would benefit by cutting its tax to $\Pi_{A B}-\varepsilon>0$ in order to attract a firm, boosting the nation's consumer surplus and its tax revenue. ${ }^{12}$ Therefore, both firms will be induced to enter the industry in equilibrium. The question is whether production is dispersed or co-located. The formal proof, in the appendix, addresses this issue.

\section{Market Size Asymmetries}

We now let country $A$ be $n>1$ times larger than $B$. Increasing $n$ raises the pre-tax profits of an entrant firm regardless of its location. However, a rise in $n$ benefits a firm located in country $A$ more than one located in $B$ because the former enjoys local access to the larger product market. In this asymmetric environment, two questions naturally arise. First, does an equilibrium with the qualitative features of the FPE equilibrium (i.e., dispersed production, and zero after-tax profits) continue to exist? Second, do qualitatively new equilibria arise, such as might involve co-location of the firms?

Throughout this section we will assume that the plant cost $C$ is sufficiently small to make pre-tax profits positive in all location configurations. ${ }^{13}$ This assumption has an important implication, noted in the proof of Proposition 2 above. It means that both firms will enter the industry in any equilibrium. Therefore, the key question is whether production is internationally dispersed or co-located.

We first consider the conditions for a dispersed equilibrium, $[A, B]$, determining the

\footnotetext{
${ }^{12}$ If the initial, putative equilibrium were $[\varnothing, \varnothing]$, then $A$ 's deviation would lead to $[A, \varnothing]$. If it were $[B, \varnothing]$, then $A$ 's deviation could produce either $[A, B]$ or $[A, \varnothing]$ (see Figure 1). The key point is that tax-cutting means that $A$ attracts a firm, and it may also lead to an extra entrant into the industry.

13 The sole exception to this is in the existence result in Proposition 3(i).
} 
equilibrium tax levels and, specifically, whether FPE will continue. Assume that the countries set $\left(T_{A}, T_{B}\right)=\left(\Pi_{A B}, \Pi_{B A}\right)$ in anticipation of dispersed production. The issue is whether, in response to such FPE taxes, the firms choose to locate in different countries. Because $\Pi_{A A}<\Pi_{A B}$ for all $n \geq 1$, it is clear that the firm in $B$ will not deviate to join its rival in country $A$. With FPE taxes, the firm earns zero post-tax profits in $B$, but would make a post-tax loss if it moved to country $A$. As long as $\Pi_{B B}<\Pi_{B A}$, we can apply the same logic to rule out a move by the firm in $A$ into country $B$. With $\Pi_{B B}<\Pi_{B A}$, relocating from $A$ to $B$ competes pre-tax profits down and leads to post-tax losses if $T_{B}=\Pi_{B A}$.

However, $\Pi_{B B}<\Pi_{B A}$ does not hold for all $n>1$. Specifically:

$$
\Pi_{B B}<\Pi_{B A} \text { if and only if } n<\bar{n} \equiv \frac{\pi_{L F}-\pi_{L L}}{\pi_{F F}-\pi_{F L}}=\frac{2(\alpha-w)+\tau}{2(\alpha-w)-3 \tau}
$$

Therefore, if $n>\bar{n}$ so $\Pi_{B B}>\Pi_{B A}$, then the firms will optimally co-locate in country $B$ in response to FPE taxes of $\left(T_{A}, T_{B}\right)=\left(\Pi_{A B}, \Pi_{B A}\right)$. This means that we can only hope to generalize the symmetric, baseline equilibrium (i.e., dispersed production plus FPE) for values of $n \in(1, \bar{n}] .{ }^{14}$ With $n>\bar{n}$, the viability of the FPE equilibrium is destroyed by the strong incentive for relocation that is offered by a low corporate tax in $B$. The reason why $\Pi_{B B}$ overtakes $\Pi_{B A}$ as $n$ rises is as follows. If country $A$ 's market becomes very large relative to that of $B$, then a firm in $B$ would prefer its rival to locate in $B$ as well because co-location would cut competition and boost profits on the significantly larger product market, with the rise in export profits outweighing the fall in domestic profits on market $B$.

Assume that $n \in(1, \bar{n}]$ so that $\left(T_{A}, T_{B}\right)=\left(\Pi_{A B}, \Pi_{B A}\right)$ leads to locations of $[A, B]$. We now investigate when these tax rates will be an equilibrium. Clearly, $n>1$ implies that the countries are no longer identical, so there are two conditions to rule out tax cutting, both analogous to (10). Country $A$ prefers attracting one firm to cutting its tax and attracting

\footnotetext{
14 Note that $\bar{n}$ equals 1 under free trade $(\tau=0)$ and is increasing in $\tau$, reaching a maximum value of 5 when the trade barrier is prohibitive $(\tau=\bar{\tau})$.
} 
both firms if and only if

$$
n S_{L F}+\Pi_{A B} \geq n S_{L L}+2 \Pi_{A A} .
$$

Expanding the profit terms, and rearranging, yields a lower limit on a firm's fixed costs such that $C \geq \underline{C_{A}}$, where

$$
\underline{C_{A}} \equiv n\left(S_{L L}-S_{L F}\right)+2\left(n \pi_{L L}+\pi_{F F}\right)-\left(n \pi_{L F}+\pi_{F L}\right) .
$$

The equivalent condition to rule out tax cutting by country $B$ is

$$
S_{L F}+\Pi_{B A} \geq S_{L L}+2 \Pi_{B B} .
$$

Expanding the profit terms, and rearranging, yields a lower limit on a firm's fixed costs such that $C \geq \underline{C_{B}}$, where

$$
\underline{C_{B}} \equiv S_{L L}-S_{L F}+2\left(\pi_{L L}+n \pi_{F F}\right)-\left(\pi_{L F}+n \pi_{F L}\right) .
$$

By analogy to (12), there are also two conditions to rule out tax-increasing deviations, that would drive the local firm out of the industry. These are

$$
C \leq \overline{C_{A}} \equiv n\left(S_{L F}-S_{F \varnothing}\right)+\left(n \pi_{L F}+\pi_{F L}\right)
$$

for country $A$ and

$$
C \leq \overline{C_{B}} \equiv S_{L F}-S_{F \varnothing}+\left(\pi_{L F}+n \pi_{F L}\right)
$$

for country $B$. Straightforward algebra shows that $\overline{C_{A}}>\overline{C_{B}}>\underline{C_{A}}>\underline{C_{B}}$ for all $n<\bar{n}$.

Proposition 3 sums up our generalization of the dispersed-production, FPE equilibrium.

\section{Proposition 3 (dispersed equilibrium with FPE)}

Assume that the size differential is sufficiently small, $n \leq \bar{n}$, such that $\Pi_{B A} \geq \Pi_{B B}$.

(i) A subgame perfect Nash equilibrium with dispersed production and FPE exists if and only if $C \in\left[\underline{C_{A}}, \overline{C_{B}}\right]$, which is a non-empty interval on all nonprohibitive $\tau$. 
(ii) If we additionally assume that pre-tax profits are positive in all location configurations, then a dispersed equilibrium with FPE exists if and only if $C \in\left[\underline{C_{A}}, \pi_{L L}+n \pi_{F F}\right]$. This interval is smaller than that in $(i)$ and non-empty on $n \leq n^{*} \equiv \frac{4 \tau}{4(\alpha-w)-5 \tau}$, where $n^{*} \in[0, \bar{n})$ for all nonprohibitive $\tau$.

Part (ii) of Proposition 3 introduces $n^{*}$, the largest size difference that is compatible with production dispersion and FPE in equilibrium if pre-tax profits are positive. We note that $n^{*}>1$ on $\tau \in\left(\frac{4}{9}(\alpha-w), \bar{\tau}\right]$. Moreover, $n^{*}$ rises with $\tau$, reaching $\frac{4}{3}$ at $\tau=\bar{\tau} .{ }^{15}$

Before turning to consider the conditions for a co-located equilibrium, we need to determine whether a dispersed $[A, B]$ equilibrium is possible when $n>\bar{n} \cdot{ }^{16}$ From our discussion above, we know that such an equilibrium could not involve FPE. Moreover, it turns out that no such equilibrium exists, for the following reasons. With $n>\bar{n}$, the firms would choose locations $[B, B]$ in response to $\left(T_{A}, T_{B}\right)=\left(\Pi_{A B}, \Pi_{B A}\right)$. Therefore, to obtain $[A, B]$ as a location equilibrium with $n>\bar{n}, T_{A}$ must be below $\Pi_{A B}$ to stop the firm in $A$ relocating to $B$. The largest $T_{A}$ that satisfies this requirement will make the firm in $A$ approximately indifferent between $A$ and $B$, given that the other firm is in $B$. However, in response to that $T_{A}$ value, country $B$ would optimally cut $T_{B}$ infinitesimally and attract both firms, undermining the possibility of production dispersion in equilibrium.

We now investigate the conditions for a co-located equilibrium. Specifically, we focus on $[A, A]$, the case where both firms locate in larger country $A .{ }^{17} \quad$ Let country $B$ offer a subsidy of $T_{B}=-\left(S_{L F}-S_{F F}\right)$, which is a corporate subsidy equal to its valuation of a single

\footnotetext{
${ }^{15}$ As in the discussion of Proposition 1, imposing the assumption of positive equilibrium taxes would be less demanding. To see this, note that $\Pi_{B A} \equiv \pi_{L F}+n \pi_{F L} \geq \underline{C_{A}}$ if and only if $n \leq \frac{4(\alpha-w)+6 \tau}{8(\alpha-w)-11 \tau}$, where the right-hand side exceeds 1 if and only if $\tau \geq \frac{4}{17}(\alpha-w)$ (though it remains less than $\bar{n}$ ).

16 The argument in this paragraph is more fully developed in Ferrett and Wooton (2005).

17 We show in Ferrett and Wooton (2005) that co-location in country $B$ is impossible in equilibrium. Essentially, this is because country $A$ has a greater willingness to subsidise inward FDI.
} 
plant and ensures that both firms will enter the industry (given positive pre-tax profits). In response, country $A$ optimally sets $T_{A}$, effectively choosing between three location pairs, $[A, A],[A, B]$ and $[B, B]$. In order to attract both firms, country $A$ will set $T_{A}$ so that

$$
\Pi_{A A}-T_{A}=\Pi_{B A}-T_{B}+\varepsilon \Rightarrow T_{A}=\Delta_{A}+T_{B}-\varepsilon
$$

In order to attract just one firm, country $A$ will set $T_{A}$ so that

$$
\Pi_{A B}-T_{A}=\Pi_{B B}-T_{B}+\varepsilon \Rightarrow T_{A}=\Delta_{B}+T_{B}-\varepsilon
$$

Country $A$ 's social welfare is: $n S_{L L}+2 T_{A}$ if it hosts both firms; $n S_{L F}+T_{A}$ if it hosts just one firm; and $n S_{F F}$ if it hosts neither. Therefore, a co-located equilibrium requires that country $A$ prefers hosting both firms with a tax of (20) to the alternatives of hosting one firm with a tax of (21) or hosting neither firm. Formally,

$$
n S_{L L}+2\left(\Delta_{A}+T_{B}\right) \geq \max \left\{n S_{L F}+\Delta_{B}+T_{B}, n S_{F F}\right\}
$$

subject to $T_{B}=-\left(S_{L F}-S_{F F}\right)$. Straightforward algebra shows that this condition holds if $n$ is sufficiently large. ${ }^{18}$ Country $A$ 's willingness to pay for additional firms is derived from the consumer-surplus benefits of inward FDI, which increase in line with $n$, and yields our result. Proposition 4 sums up our analysis of co-location.

\section{Proposition 4 (co-located equilibrium)}

Assume that pre-tax profits are positive in all location configurations.

(i) A subgame perfect Nash equilibrium exists with firm co-location in the larger country and strictly positive post-tax profits if and only if $n \geq n^{* *} \equiv \frac{12(\alpha-w)+5 \tau}{12(\alpha-w)-17 \tau}$, where $n^{* *} \in(1, \bar{n})$ for all $\tau \in(0, \bar{\tau})$.

\footnotetext{
18 The first argument in $\max \{\cdot\}$ is the one that binds.
} 
(ii) Because $n^{* *}>n^{*}$ on all nonprohibitive $\tau$, there is either a unique perfect equilibrium or no equilibrium in pure strategies.

As $T_{B}<0$, country $B$ offers a subsidy, it is clear from (20) that post-tax profits in the co-location equilibrium, $\Pi_{A A}-T_{A}$, must be positive. However, it is also the case that, for sufficiently large $n, T_{A}>0$ in the co-location equilibrium despite the offer of a subsidy by B. This mirrors the result in Haufler and Wooton (1999) where a large country is able to impose a corporate tax while retaining FDI, despite the offer of a subsidy by the smaller country. Such a tax is possible because of the superior product-market access offered by the larger country.

\section{Conclusion}

Our central result concerns the outcome of the competition between two identical countries to attract the investment of two identical firms. We show that an equilibrium exists where production is internationally dispersed and all profits are captured in tax by the host countries. This "race to the top" contrasts strikingly with the "race to the bottom" observed in the tax/subsidy competition between two identical countries for a monopoly firm's plant.

We investigate the robustness of this central result to changes in the relative sizes of the competing countries. We assume that the plant cost is small enough to make pre-tax profits positive in all location configurations and show that this implies that both firms will enter the industry in equilibrium. The question is whether the firms are internationally dispersed or locate in the same country. If an equilibrium exists, it is unique. For a sufficiently small degree of size asymmetry between the countries, the equilibrium is qualitatively identical to that in the baseline, symmetric case in that production is dispersed and profits are fully extracted by taxes. For a larger degree of size asymmetry, however, both firms may locate in the larger country and earn strictly positive post-tax profits. 
Our interest lies in the outcomes of tax/subsidy competition in situations where both firms and host countries care about production locations. Trade costs are an especially simple way of creating such an environment, as consumers would rather have (cheaper) locally produced goods than imports, while these trade costs also mean that a firm cares about its own location and that of its rival. However, our results are not limited to the particular specification of the model that we have used. For example, government concerns about the location of MNEs' plants often appear primarily driven by the relief of involuntary unemployment and the promotion of technology spillovers to indigenous firms. We argue that these wider governmental motivations are qualitatively identical to those of our driving force of increasing consumer surplus. In order to introduce explicitly these additional host-country incentives, we would need to impose additional structural assumptions. These would complicate the analysis without altering the qualitative results. Essentially, the simple expedient of trade costs allows us to build the minimal model of tax/subsidy competition where location matters to both firms and host countries.

We have imposed linearity assumptions on the cost and demand functions, and this makes it straightforward for us to derive closed-form solutions. However, we believe that our qualitative results would survive with more general (but well-behaved) functional forms, given that linearity is not a necessary part of our explanation. For example, it is the geographic structure of our model, specifically the existence of trade costs, that underlies our central result on the existence of equilibrium with internationally dispersed production and FPE. Firm co-location intensifies competition and competes profits down, resulting in the firms locating in different countries in our baseline equilibrium. Furthermore, for any cost/demand functions, the two critical levels of the plant fixed $\operatorname{cost} C$ between which our baseline equilibrium exists will continue to be given by conditions (10) and (12). Different functional forms 
would merely alter the specific expressions for consumer surplus and per-capita profits.

A further set of possible extensions centres around altering the policy instruments available to the host countries. The assumptions we make of lump-sum taxes/subsidies, balanced government budgets, and non-discrimination between the two firms are very simple and facilitate a clear analysis. In practice, of course, governments have a much richer menu of policy instruments and options available and therefore more degrees of freedom than in our model. An interpretation of our central result that we favour is that it demonstrates that governments do not need a large policy space in order to appropriate the entire social surplus generated in a mobile industry. Moreover, we conjecture (following Haufler and Wooton, 1999) that our result would survive if proportional profits taxes were substituted for the lump-sum taxes we have used. ${ }^{19}$

We might allow for more host countries and/or firms. It seems clear that the logic of our arguments and, by extension, our qualitative results should readily generalize to many other specifications with oligopoly in the product markets. With $g$ countries of a "similar" size and $k$ firms (where $k \geq g$ and $k / g$ an integer), we anticipate the possibility of constructing an FPE taxation equilibrium where each country hosts $k / g$ firms. ${ }^{20}$ In this case, the tradeoffs facing each country would be the same as those in our baseline model with identical countries. Under FPE, the government effectively reimburses firms' plant investment costs and then taxes away of all their variable profits. Therefore, a taxation equilibrium with FPE requires that the plant cost be neither so low that attracting additional inward FDI is affordable nor so large that increasing corporate taxes and driving firms away is worthwhile.

\footnotetext{
${ }^{19}$ For example, a perfect equilibrium with internationally dispersed production and a corporate tax rate of 100 per cent on positive profits clearly exists if the plant cost $C$ is such that pre-tax profits are strictly positive with dispersed production but strictly negative under co-location.

${ }^{20}$ In the 2-country, $k$-firm oligopoly model of Haufler and Wooton (2007), there is an equilibrium in which the governments set FPE taxes in the symmetric case and each country gets $k / 2$ of the firms. This arises only at one critical level of trade costs because $k$ is treated as as continuous, rather than as an integer.
} 
We also conjecture that the analysis of the large size-asymmetry case is generalizable to more than two firms, but sticking with two host countries. Haufler and Wooton (2007) investigate the effects of trade integration (the reduction in trade costs) on the level of taxes, the location of firms, and national welfare in a setting identical to ours except for there being a large, but fixed, number of firms in the industry. For a given size asymmetry and at sufficiently high trade costs, a dispersed FPE equilibrium exists. Firms increasingly aggolomerate in the larger market as trade costs decline until eventually the larger country attracts all the firms, the smaller country posts a subsidy equal to its valuation for a single firm, and the larger country's tax bid just trumps its rival's bid. 


\section{References}

Black, Dan A., and William H. Hoyt (1989). "Bidding for Firms." American Economic Review 79(5), 1249-1256.

Bjorvatn, Kjetil and Carsten Eckel (2006), "Policy Competition for Foreign Direct Investment between Asymmetric Countries." European Economic Review 50, 18911907.

Brander, J. A., and Spencer, B. J. (1985). "Export Subsidies and International Market Share Rivalry." Journal of International Economics 18, 83-100.

Caves, R. (1996), Multinational Enterprise and Economic Analysis, Cambridge University Press.

Davies, S., and Lyons, B. (1996), Industrial Organization in the European Union: Structure, Strategy and the Competitive Mechanism, Oxford University Press.

Devereux, Michael P., Rachel Griffith, and Alexander Klemm (2002). "Corporate Income Tax Reforms and International Tax Competition." Economic Policy 17, 450-495.

European Commission (1997). "Towards Tax Co-ordination in the European Union: A Package to Tackle Harmful Tax Competition." Communication from the European Commission COM(97) 495 final.

Ferrett, Ben, and Ian Wooton (2005), "Competing for a Duopoly: International Trade and Tax Competition." CEPR Discussion Paper number 5379, November.

Ferrett, Ben, and Ian Wooton (2006), "Tax Competition and the International Distribution of Firm Ownership: An Invariance Result." CEPR Discussion Paper number 5984, December.

Fumagalli, Chiara (2003), "On the Welfare Effects of Competition for Foreign Direct Investments." European Economic Review 47, 963-983.

Gray, J. (1998). False Dawn: The Delusions of Global Capitalism. London: Granta Books.

Haaparanta, Pertti (1996). "Competition for Foreign Direct Investments." Journal of Public Economics 63, 141-153.

Haufler, Andreas, and Ian Wooton (1999), "Country Size and Tax Competition for Foreign Direct Investment." Journal of Public Economics 71, 121-139.

Haufler, Andreas, and Ian Wooton (2007), "Competition for Firms in an Oligopolistic Industry: Do Firms or Countries Have to Pay?" CESifo Working Paper number 1976, April.

Head, Keith (1998). "Comment on Doms and Jensen." In Robert Baldwin, Robert Lipsey, and J. David Richardson (eds.), Geography and Ownership as Bases for Economic Accounting. Chicago: The University of Chicago Press, pp. 255-258.

Janeba, E. (1998). "Tax Competition in Imperfectly Competitive Markets." Journal of International Economics 44(1), 135-153. 
King, Ian, R. Preston McAfee, and Linda Welling (1993). "Industrial Blackmail: Dynamic Tax Competition and Public Investment." Canadian Journal of Economics 26(3), 590-608.

Kozul-Wright, R., and Rowthorn, R. (1998). "Spoilt for Choice? Multinational Corporations and the Geography of International Production." Oxford Review of Economic Policy 14(2), 74-92.

Markusen, James R., Edward R. Morey, and Nancy Olewiler (1996). "Competition in Regional Environmental Policies When Plant Locations are Endogenous." Journal of Public Economics, 56, 55-77.

Menezes, Flavio M. (2003). "An Auction Theoretical Approach to Fiscal Wars." Social Choice and Welfare 20, 155-166.

OECD (1998). Harmful Tax Competition: An Emerging Global Issue. Paris: Organisation for Economic Co-operation and Development.

Olsen, Trond E., and Petter Osmundsen (2003). "Spillovers and International Competition for Investments." Journal of International Economics 59, 211-238.

Ottaviano, Gianmarco I. P., and Tanguy van Ypersele (2005). "Market Size and Tax Competition." Journal of International Economics 67, 25-46.

UNCTAD (1997), World Investment Report 1997: Transnational Corporations, Market Structure and Competition Policy, United Nations: New York and Geneva.

Zodrow, G. and Mieszkowski, P. (1986). "Pigou, Tiebout, Property Taxation and the Underprovision of Local Public Goods." Journal of Urban Economics 19, 356-370. 


\section{Appendix: Proof of Proposition 2}

We split up Figure 1 and consider each part in turn.

(i) Country $A$ can profitably deviate from any point in $[\varnothing, \varnothing]$ or $[B, \varnothing]$ by setting a positive $\operatorname{tax}$ of $T_{A}=\Pi_{A B}-\varepsilon$. Through this deviation, $A$ gains both consumer surplus and tax revenue. Likewise, country $B$ can profitably deviate from any point in $[\varnothing, \varnothing]$ or $[A, \varnothing]$ by setting a positive tax of $T_{B}=\Pi_{B A}-\varepsilon$.

(ii) Point $E$ is the only possible equilibrium point in the $[A, B]$ region. At least one of the countries can profitably deviate from any other point in $[A, B]$ by raising its tax without upsetting the firms' location choices.

(iii) The only possible equilibrium points in $[A, A]$ and $[B, B]$ are, respectively, along the NW and SE boundaries as a host can profitably deviate from any other point by raising its tax. Moreover, country $B$ can deviate from any point along the $[A, A]$ boundary in the NE and SE quadrants by cutting $T_{B}$ and stealing a firm from $A$. This is profitable as it can be achieved keeping $T_{B}$ positive. Likewise, country $A$ can profitably deviate from points along the $[B, B]$ boundary in the NE and NW quadrants by cutting $T_{A}$.

(iv) Aside from point $E$, the remaining possible equilibrium points lie along the boundaries of the $[A, A]$ and $[B, B]$ regions in the SW quadrant, where the firms would co-locate. The following condition rules out an equilibrium inside $[A, A]$ (and, due to symmetry, rules out an equilibrium inside $[B, B])$. Given that $T_{B}=-\left(S_{L F}-S_{F F}\right)$, the maximum subsidy country $B$ is prepared to pay for a single firm, country $A$ prefers hosting one firm to both if and only if $S_{L F}+\Delta_{B}+T_{B} \geq S_{L L}+2\left(\Delta_{A}+T_{B}\right)$. The left-hand side of this inequality is $A$ 's social welfare if it deviates to the top of the $[A, B]$ region. Straightforward algebra shows that this condition holds for all nonprohibitive $\tau$. 


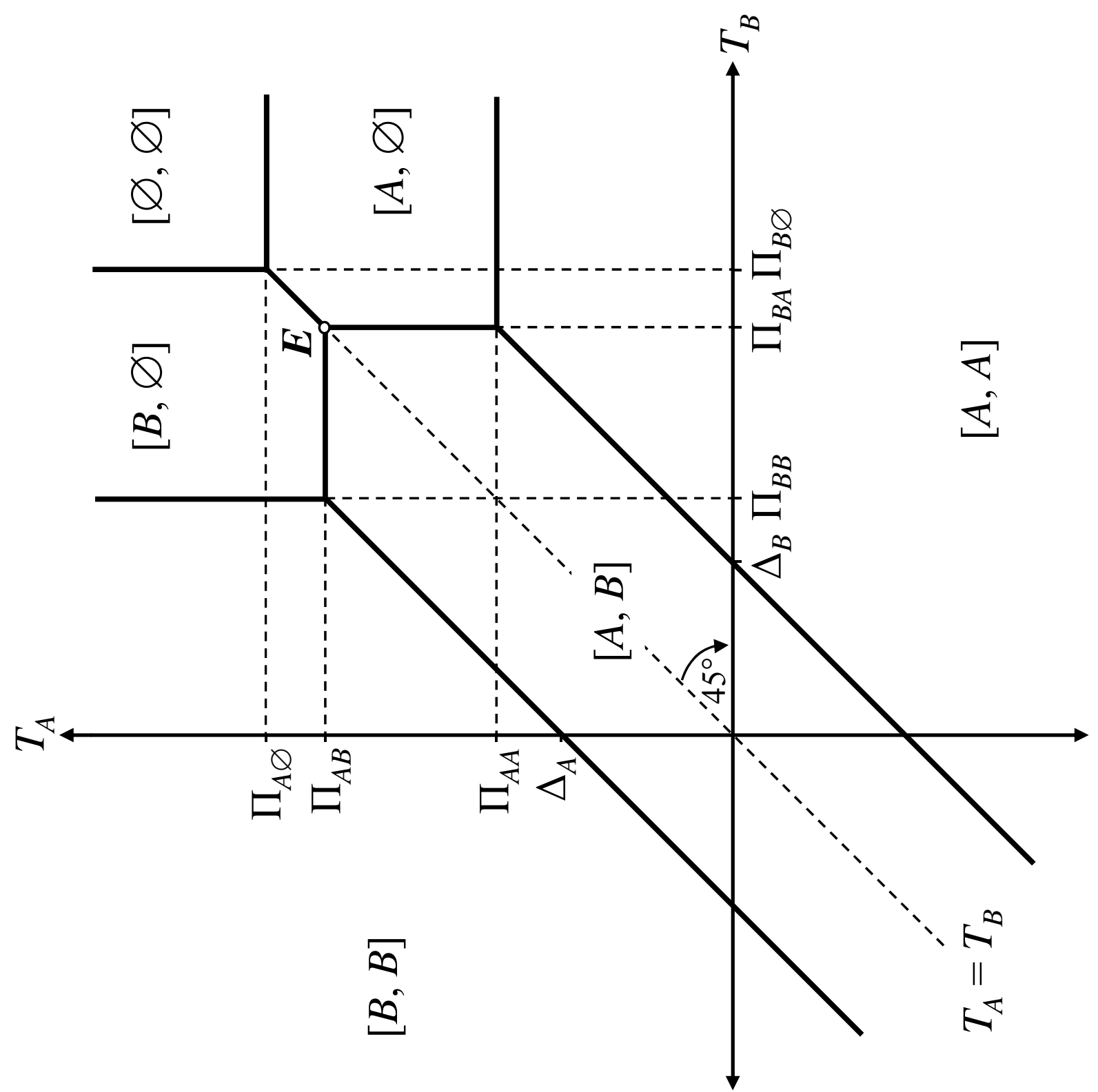

0
0
0
0
0
0
0
0
0
0
0

릉

寻

告

ב⿱ 